\title{
Detection rate and genotyping of Cryptosporidium spp. and its relation to copro TNF- $\alpha$ in elderly Egyptians attending outpatient clinics of Cairo University Hospitals
}

Original

Noha M Amin ${ }^{1}$, Amira Raafat ${ }^{1}$, Salwa M Morsy ${ }^{1,2}$

Departments of Medical Parasitology, Faculty of Medicine, Cairo University ${ }^{1}$ and Faculty of Medicine, Modern University for Technology and Information², Cairo, Egypt

\begin{abstract}
Background: Elderly individuals are considered an at-risk population, susceptible to enteric infections; and Cryptosporidium spp. is an apicomplexan protozoan considered to be one of the most common protozoa causing diarrhea. Cryptosporidiosis causes elevation of many pro-inflammatory cytokines like tumor necrosis factor-alpha (TNF- $\alpha$ ) which may play a role in pathogenesis of the disease.

Objectives: This study was designed for detection and genotyping of Cryptosporidium spp. in elderly patients and the relationship of infection with copro TNF- $\alpha$. Diagnosis was by evaluation of permanent acid-fast cold Kinyoun's (AF) staining, immunochromatographic detection (ICT), and ELISA in comparison to molecular diagnosis as gold standard diagnostic method.

Subjects and Methods: Stool samples were collected from 270 elderly patients aged above 60 years old attending outpatient clinics of Internal Medicine Hospital, Cairo University. Samples were examined microscopically by direct wet mount, and AF staining, and then subjected to ICT, ELISA, and nested PCR (nPCR) assays. Positive samples by nPCR were then subjected to Restriction fragment length polymorphism (RFLP) to detect Cryptosporidium genotypes. Copro-levels of TNF- $\alpha$ were measured to assess their relationship with cryptosporidiosis.

Results: Cryptosporidiosis detection rates of 3.7\%,6.3\%, 6.7\%, 3.7\% were determined by microscopic examination after AF staining, ICT, ELISA and nPCR, respectively. When RFLP was performed on nPCR positive samples, eight and two samples were assigned as genotype 1 and 2 , respectively. Moreover, TNF- $\alpha$ was significantly correlated with cryptosporidiosis.

Conclusion: The elderly are highly vulnerable to cryptosporidiosis. Immunodiagnosis and molecular techniques are fundamental for the diagnosis of cryptosporidiosis. Cryptosporidiosis significantly affects copro TNF- $\alpha$.
\end{abstract}

Keywords: AF stain, elderly, Cairo, Cryptosporidium spp., ELISA, ICT, nested PCR.

Received: 27 November, 2020, Accepted: 30 March, 2021.

Corresponding Author: Noha M Amin, Tel.: +20 1013429009, E-mail: nmabdelrazek@kasralainy.edu.eg

Print ISSN: 1687-7942, Online ISSN: 2090-2646, Vol. 14, No. 1, April, 2021.

\section{INTRODUCTION}

Cryptosporidium spp. are apicomplexan protozoa causing intestinal disorders including diarrhea in humans worldwide ${ }^{[1]}$. Infection can be transmitted mainly by the consumption of contaminated food and water containing the infective oocysts ${ }^{[2]}$. The symptoms of acute infection with cryptosporidiosis involve severe watery diarrhea, nausea, abdominal pain, low-grade fever, malabsorption, malnutrition; leading to dehydration ${ }^{[3-5]}$. The disease is usually self-limited in immunocompetent individuals and proceeds to chronic and life-threatening conditions in immunocompromised patients ${ }^{[6]}$. The elderly population may be particularly sensitive to cryptosporidiosis and this may be attributed to changes in the immune system and gastrointestinal functions that occur with aging, leading to increased susceptibility to enteric infections ${ }^{[7,8]}$. Since 1998, the recorded annual rate of cryptosporidiosis in the United States among persons aged $\geq 65$ years varied between 0.29 and 0.70 cases per 100,000 populations. This minimal number of cases is attributed to the non-obligatory reporting to the $\mathrm{CDC}^{[9]}$. Moreover, Cryptosporidium spp. are considered to be a main cause of waterborne outbreaks worldwide, and there are 239 waterborne outbreaks reported between 2011 and $2016^{[10]}$. Thus, in 2004, the WHO listed it among the globally "neglected diseases", linked with poverty in most developing countries ${ }^{[11]}$.

Cryptosporidiosis is mainly diagnosed by microscopic detection of oocysts in stained stool smears $^{[3]}$. To facilitate and improve testing, coproantigen commercial tests, such as ICT, and ELISA were used, because they are rapid, simple, cost-effective and don't depend on microscopy skills ${ }^{[12,13]}$. Later, molecular techniques including polymerase chain reaction (PCR) based assays have become reference methods that offer sensitive and specific diagnosis of Cryptosporidium spp. ${ }^{[14]}$, in addition to identification of infecting species ${ }^{[6]}$. Concerning this issue, several molecular studies have revealed that different species of Cryptosporidium may infect man. Currently, more than 26 species and nearly 50 genotypes have been documented in humans and animals ${ }^{[15]}$. The human 
cases of cryptosporidiosis are mainly caused by two species: C. parvum and C. hominis ${ }^{[16]}$. However, other species as $C$. felis, $C$. canis, $C$. meleagridis, $C$. muris, and $C$. suiscan also infect humans ${ }^{[17]}$.

It was observed that cryptosporidiosis correlates with the elevation of many pro-inflammatory cytokines such as TNF- $\alpha$ and interleukin (IL)-1 $\beta$; these cytokines are key stimulators of prostaglandin synthesis ${ }^{[18]}$. In the intestinal wall, prostaglandins are expressed in response to these pro-inflammatory cytokines and may contribute to diarrhea by altering chloride secretion. Thus, TNF- $\alpha$, IL- $1 \beta$ and prostaglandins have been assumed to have a role in the pathogenesis of cryptosporidiosis $^{[19]}$.

The aim of our study is to relate cryptosporidiosis in elderly patients to copro TNF- $\alpha$. Simultaneously, we compared the diagnostic sensitivity and specificity of the AF stain, and the commercially available coproantigen tests; Cryptosporidium ELISA, and RIDA ${ }^{\circledR}$ QUICK-ICT against PCR as the reference method ${ }^{[20,21]}$.

\section{SUBJECTS AND METHODS}

This descriptive analytical study was conducted at Medical Parasitology, and Clinical Pathology departments, Cairo University, Faculty of Medicine during the period from May 2019 to June 2020.

Subjects: The study included 270 elderly diarrheic patients who were selected from Internal Medicine Hospital, outpatients' clinic, Cairo University. Inclusion criteria include both sexes, aged above 60 years, with diarrhea. The patient was considered diarrheic when complaining of abnormal increase in stool liquidity and frequency of bowel motions. Patients were subjected to thorough history taking including type of drinking water, level of education, residence, vomiting, history of hepatitis $\mathrm{C}$, and abdominal pain, as well as clinical examination.

Stool samples collection: A single fecal sample from each patient was collected in a dry, clean, leak-proof plastic container. The macroscopic examination of the fecal samples was recorded before processing. Each sample was divided into 2 parts; fresh and frozen at $-20^{\circ} \mathrm{C}$.

\section{Detection rate of cryptosporidiosis}

1.Microscopic examination: The stool samples were first examined by direct wet mount after the addition of a drop of iodine, and by formalin-ethyl acetate sedimentation techniques to aid visualization of protozoa cysts, helminthes eggs and larvae.

2.Permanent cold AF Kinyoun's staining: Thin stool smears were prepared from the sediment obtained by the formalin ethyl acetate sedimentation procedure and stained with cold AF stain for detection of oocysts. A commercially available readily prepared AF stain was used (Kinyoun Kit cat no 25765-1, Polysciences, Germany). Oval/round bodies, about 4-5 $\mu \mathrm{m}$, of Cryptosporidium oocysts stained pink to red to deep purple, often with darker staining around the periphery, were identified against a blue background. In some of the oocysts, four sporozoites were visible ${ }^{[22]}$.

3.Immunochromatographic test (ICT): Fresh samples were also processed using RIDA $^{\circledR}$ QUICK Cryptosporidium test (Biopharm, Germany) for the qualitative determination of $C$. parvum in stool samples. This test is a fast single-step ICT in which the sample was positive if the red and blue bands are visible, the sample was negative if only the blue band is visible and not valid if there were no visible bands. Likewise, changes in band color that appear after 10 minutes or later were also without any diagnostic value and not used for evaluation.

4.Enzyme linked immunosorbent assay (ELISA): Part of each frozen fecal specimens was processed for detection of Cryptosporidium copro-antigen using RIDASCREEN ${ }^{\circledR}$ Cryptosporidium ELISA (Cryptosporidium-C1201, Germany) according to the manufacturer's instructions ${ }^{[23]}$. In order to establish the cut-off point, extinction units (0.15) were added to the measured extinction for the negative control. The specimen was considered positive if the extinction rate was $10 \%$ higher than the calculated cut-off value, while samples with extinctions $10 \%$ less than calculated cut-off were considered negative.

5.Nested PCR (nPCR) ${ }^{[24,25]}$ : In this study, nPCR was considered the gold standard method for diagnosis of cryptosporidiosis ${ }^{[20,21]}$. Genomic DNA extraction from stool samples was done using FavorPrepTM

Table 1. The thermocycler program for nPCR reactions.

\begin{tabular}{llcccc}
\hline \hline \multirow{2}{*}{ Steps } & \multicolumn{2}{c}{ Process } & \multicolumn{2}{c}{ Primary reaction } & \multicolumn{2}{c}{ Secondary reaction } \\
\cline { 3 - 5 } & & Temp. & Time & Temp. & Time \\
\hline $\mathbf{1}$ & Initial denaturation & $95^{\circ} \mathrm{C}$ & $4 \mathrm{~min}$ & $95^{\circ} \mathrm{C}$ & $4 \mathrm{~min}$ \\
$\mathbf{2}$ & Denaturation & $94^{\circ} \mathrm{C}$ & $1 \mathrm{~min}$ & $94^{\circ} \mathrm{C}$ & $50 \mathrm{sec}$ \\
$\mathbf{3}$ & Annealing & $63^{\circ} \mathrm{C}$ & $1 \mathrm{~min}$ & $54^{\circ} \mathrm{C}$ & $30 \mathrm{sec}$ \\
$\mathbf{4}$ & Extension & $72^{\circ} \mathrm{C}$ & $1 \mathrm{~min}$ & $72^{\circ} \mathrm{C}$ & $50 \mathrm{sec}$ \\
$\mathbf{5}$ & Final extension & $72^{\circ} \mathrm{C}$ & $10 \mathrm{~min}$ & $72^{\circ} \mathrm{C}$ & 35 \\
$\mathbf{6}$ & Infinite & $4^{\circ} \mathrm{C}$ & $\infty$ & $4^{\circ} \mathrm{C}$ & $10 \mathrm{~min}$ \\
\hline \hline
\end{tabular}


stool DNA isolation Mini Kit (Cat. No. FASTI 001 Favorgen Biotech corporation Ping-Tung, Taiwan). Extracted copro-DNA was amplified by nPCR (Table 1) targeting the gene encoding Cryptosporidium oocyst wall protien (COWP). Primers used to amplify $796 \mathrm{bp}$ fragment were BCOWPF (5-ACC GCT TCT CAA CAA CCA TCT TGT CCT C-3) and BCOWPR (5CGC ACC TGT TCC CAC TCA ATG TAA ACC C-3) ${ }^{[24]}$. Nested primers to amplify 553 bp fragment were Cry-15 (5-GTA GAT AAT GGA AGA GAT TGT G-3) and Cry-9 (5-GGA CTG AAA TAC AGG CAT TAT CTT $G-3)^{[25]}$. The volume of reaction in the $1^{\text {ry }}$ and $2^{\text {ry }}$ reactions was $25 \mu \mathrm{l}$ including $12.5 \mu \mathrm{l}$ PCR master mix, $0.1 \mu \mathrm{l}$ Taq polymerase, forward and reverse primer $1 \mu \mathrm{l}$ each, $2 \mu \mathrm{l}$ templet DNA and distilled water up to $25 \mu$ l. Reagents used in the $1^{\text {ry }}$ and $2^{\text {ry }}$ reactions were similar, except for the templet DNA. The amplified amplicons of $553 \mathrm{bp}$ generated from the secondary reaction were subjected to $1.5 \%$ agarose gel electrophoresis and visualized by a UV trans-illuminator after being stained with ethidium bromide ${ }^{[24,25]}$.

II. Genotyping: Positive samples by nPCR were then subjected to RFLP with restriction enzyme cleavage Rsa I to determine Cryptosporidium genotypes. The reaction was performed in a volume of $30 \mu \mathrm{l}$. Included reagents were $10 \mu \mathrm{l}$ PCR product (Target DNA), $17 \mu \mathrm{l}$ Nuclease-free water, $2 \mu \mathrm{l}$ Green buffer and $1 \mu \mathrm{l}$ Rsa I Enzyme. Genotype 1 was considered if Rsa I digestion resulted in 4 bands: 34 bp, 106 bp, 125 bp and 285 bp, and genotype 2 if Rsa I digestion resulted in 3 bands: $34 \mathrm{bp}, 106 \mathrm{bp}$ and $410 \mathrm{bp}$.

III. Measurement of copro-level of TNF- $\alpha$ : This was measured by an ELISA method (Eagle Biosciences, KR9610, USA) using fecal samples according to the manufacturer's instructions ${ }^{[26]}$.
Statistical analysis: Data were coded and entered using the statistical package SPSS version 25. Data were processed using mean, standard deviation, median, minimum, and maximum in quantitative data and using frequency (count) and relative frequency (percentage) for categorical data. Comparisons between quantitative variables were done using the non-parametric MannWhitney test ${ }^{[27]}$. For comparing categorical data, Chi square $\left(X^{2}\right)$ test was performed. Fisher exact test was used instead when the expected frequency was less than five ${ }^{[28]}$. Standard diagnostic indices including sensitivity, specificity, positive predictive value (PPV), negative predictive value (NPV) and diagnostic efficacy were calculated as described elsewhere ${ }^{[29]}$. Statistical significance was considered when $P$ value was lower than 0.05 .

Ethical consideration: Participants in this study were informed of the aim of this study and a consent was taken from each. The study followed the Ethical Guidelines of Faculty of Medicine; Cairo University Institutional which agreed with the 1964 Helsinki Declaration. Cryptosporidium spp. infected cases were informed and treated.

\section{RESULTS}

The stool samples were subjected to microscopic examination after permanent AF stain, ICT, ELISA and nPCR (Figure 1). Cryptosporidium was detected in 10 (3.7\%), 17 (6.3\%), 18 (6.7\%), 10 (3.7\%) samples, respectively. Accuracy and performance of AF stain, ICT, ELISA were calculated compared to nPCR as a reference method (Table 2). Standard diagnostic indices including sensitivity, specificity, PPV, NPV and diagnostic efficacy were calculated for each technique as described in table (3).

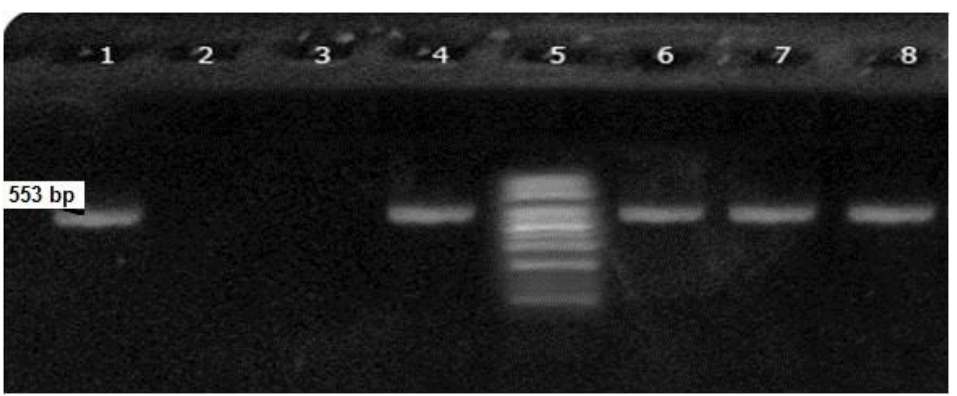

Fig. 1. Electrophoretic profiles of the PCR products amplified with the oligonucleotide primers cowp gene using nPCR for specific detection of Cryptosporidium. Lane 5: Ready-load 100 bp ladder.

Lanes 1, 4, 6-8: Positive samples (553 bp).

Lanes 2, 3: Negative samples.

Table 2. Accuracy of AF stain, ICT and ELISA compared to nPCR.

\begin{tabular}{llccc}
\hline \multicolumn{2}{l}{ Diagnostic method } & Positive [No. (\%)] & NPCR & \multicolumn{2}{c}{ Statistical analysis } \\
\hline \multirow{2}{*}{ Microscopy value }
\end{tabular}


PARASITOLOGISTS UNITED JOURNAL

Table 3. Standard diagnostic indices for each test.

\begin{tabular}{lcccccc}
\hline \hline \multirow{2}{*}{ Parameter } & \multicolumn{2}{c}{ Microscopy } & \multicolumn{2}{c}{ ICT } & ELISA \\
\cline { 2 - 7 } & Value & 95\% CI & Value & 95\% CI & Value & 95\% CI \\
\hline Sensitivity & $90.00 \%$ & $55.50 \%$ to $99.75 \%$ & $100.00 \%$ & $69.15 \%$ to $100.00 \%$ & $100.00 \%$ & $69.15 \%$ to $100.00 \%$ \\
Specificity & $99.62 \%$ & $97.88 \%$ to $99.99 \%$ & $97.31 \%$ & $94.53 \%$ to $98.91 \%$ & $96.92 \%$ & $94.03 \%$ to $98.66 \%$ \\
PPV & $90.00 \%$ & $55.73 \%$ to $98.47 \%$ & $58.82 \%$ & $40.76 \%$ to $74.79 \%$ & $55.56 \%$ & $38.72 \%$ to $71.21 \%$ \\
NPV & $99.62 \%$ & $97.58 \%$ to $99.94 \%$ & $100.00 \%$ & ---- & $100.00 \%$ & ---- \\
Accuracy & $99.26 \%$ & $97.35 \%$ to $99.91 \%$ & $97.41 \%$ & $94.73 \%$ to $98.95 \%$ & $97.04 \%$ & $94.25 \%$ to $98.71 \%$ \\
\hline \hline
\end{tabular}

ICT: Immunochromatographic test; ELISA: Enzyme-linked immunosorbent assay; CI: Confidence interval; PPV: Positive predictive value; NPV: Negative predictive value.

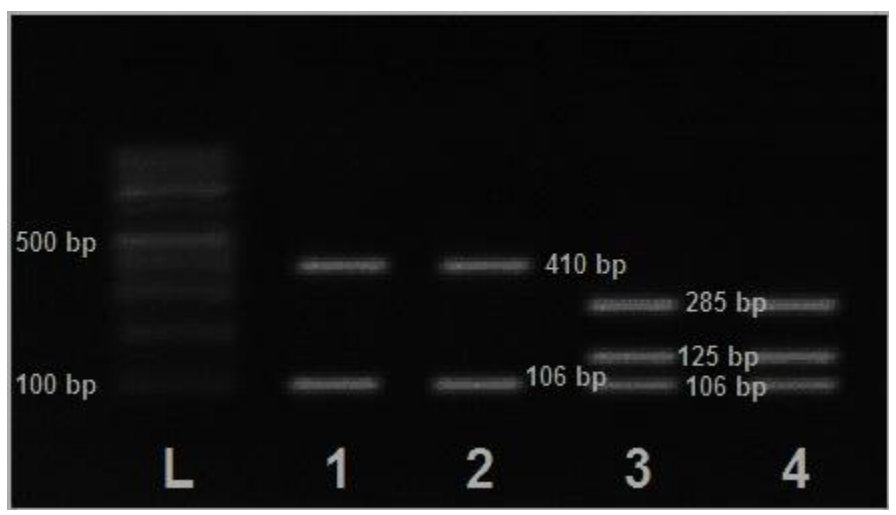

To detect Cryptosporidium genotype, RFLP was done on nPCR positive samples. Eight samples (80\%) proved to be genotype 1 , and 2 samples (20\%) proved to be genotype 2 (Figure 2).

Cryptosporidium was detected by nPCR in both sexes including $6(60 \%)$ males and $4(40 \%)$ females without any significant statistical association between sex of the patient and infection with Cryptosporidium.
Fig 2. An agarose gel electrophoresis showing RFLP products after digestion with Rsal endonuclease.

L: DNA marker ladder.

Lanes 1, 2: C. parvum genotype 2.

Lanes 3, 4: C. parvum genotype 1.

Band 34 was too small to be detected.

Table 4. Demographic and clinical data of the study population and their associated statistical significance.

\begin{tabular}{|c|c|c|c|c|}
\hline \multirow{2}{*}{\multicolumn{2}{|c|}{ Demographic and clinical data }} & \multicolumn{2}{|c|}{ nPCR } & \multirow{3}{*}{$\begin{array}{c}\text { Statistical analysis } \\
P \text { value } \\
0.533\end{array}$} \\
\hline & & \multirow{2}{*}{$\begin{array}{c}\text { Positive [No. (\%)] } \\
6(60) \\
4(40)\end{array}$} & \multirow{2}{*}{$\begin{array}{c}\text { Negative [No. (\%)] } \\
126(48.5) \\
134(51.5)\end{array}$} & \\
\hline Gender & $\begin{array}{l}\text { Male } \\
\text { Female }\end{array}$ & & & \\
\hline Residence & $\begin{array}{l}\text { Rural } \\
\text { Urban }\end{array}$ & $\begin{array}{l}7(70) \\
3(30)\end{array}$ & $\begin{array}{l}126(48.5) \\
134(51.5)\end{array}$ & 0.212 \\
\hline Drinking water & $\begin{array}{l}\text { Tape } \\
\text { Ground }\end{array}$ & $\begin{array}{l}5(50) \\
5(50)\end{array}$ & $\begin{array}{c}216(83.1) \\
44(16.9)\end{array}$ & $0.02 *$ \\
\hline Education & $\begin{array}{l}\text { High } \\
\text { Intermediate } \\
\text { Low } \\
\text { Illiterate }\end{array}$ & $\begin{array}{l}1(10) \\
4(40) \\
3(30) \\
2(20)\end{array}$ & $\begin{array}{c}215(82.7) \\
43(16.5) \\
1(0.4) \\
1(0.4)\end{array}$ & $<0.001^{*}$ \\
\hline DM & $\begin{array}{l}\text { Positive } \\
\text { Negative }\end{array}$ & $\begin{array}{l}6(60) \\
4(40)\end{array}$ & $\begin{array}{c}221(85.0) \\
39(15.0)\end{array}$ & 0.057 \\
\hline Hepatitis C & $\begin{array}{l}\text { Positive } \\
\text { Negative }\end{array}$ & $\begin{array}{l}2(20) \\
8(80)\end{array}$ & $\begin{array}{c}219(84.2) \\
41(15.8)\end{array}$ & $<0.001^{*}$ \\
\hline Corticosteroid therapy & $\begin{array}{l}\text { Positive } \\
\text { Negative }\end{array}$ & $\begin{array}{l}7(70) \\
3(30)\end{array}$ & $\begin{array}{l}125(48.1) \\
135(51.9)\end{array}$ & 0.209 \\
\hline Abdominal pain & $\begin{array}{l}\text { Positive } \\
\text { Negative }\end{array}$ & $\begin{array}{c}10(100) \\
0(0)\end{array}$ & $\begin{array}{c}223(85.8) \\
37(14.2)\end{array}$ & 0.367 \\
\hline Vomiting & $\begin{array}{l}\text { Positive } \\
\text { Negative }\end{array}$ & $\begin{array}{l}5(50) \\
5(50)\end{array}$ & $\begin{array}{c}216(83.1) \\
44(16.9)\end{array}$ & $0.02 *$ \\
\hline
\end{tabular}

nPCR: Nested polymerase chain reaction; DM: Diabetes mellitus, *: Significant $(P<0.05)$. 
high, intermediate, low to illiterate with significant statistical association between level of education and cryptosporidiosis $(P<0.001)$. Furthermore, we found a significant statistical association $(P<0.001)$ between Cryptosporidium and patients with positive history for hepatitis C; but we found no statistical significance with either diabetes mellitus or steroid treatment (Table 4). Regarding clinical manifestations, 100\% and $50 \%$ of patients with cryptosporidiosis presented with abdominal pain and vomiting respectively, being statistically significant $(P=0.02)$ with the latter (Table 4).

By examining copro-level of TNF- $\alpha$ using ELISA, it was observed that a significant statistical association existed between TNF- $\alpha$ and infection with Cryptosporidium $(P=0.02)$ (Table 5).

Table 5. Results of TNF- $\alpha$ in positive and negative cryptosporidiosis by nPCR.

\begin{tabular}{lccc}
\hline \hline & \multicolumn{2}{c}{ nPCR } & Statistical analysis \\
\cline { 2 - 4 } & Positive & Negative & \\
\hline TNF- $\alpha(\mathbf{p g} / \mathrm{ml})$ Mean \pm SD & $79.00 \pm 53.22$ & $39.23 \pm 43.39$ & $\boldsymbol{P}=\mathbf{0 . 0 2 *}$ \\
\hline \hline
\end{tabular}

nPCR: Nested polymerase chain reaction; TNF- $\alpha$ : Tumor necrosis factor-alpha; *: Significant $(P=0.020)$

\section{DISCUSSION}

The elderly are a high risk population for enteric infections due to the changes that occur in the gastrointestinal functions and the immune system with ageing ${ }^{[8]}$. Persons $>65$ years of age recorded a high risk of cryptosporidiosis with a shorter incubation period than reported in adults with an increased threat for secondary person-to-person transmission ${ }^{[30]}$. Mor et $a l^{[31]}$ observed a positive tendency for cryptosporidiosis among persons aged $\geq 65$ years. The reports indicated that Cryptosporidium constitutes the real incidence of waterborne illness, and the association may rise with an ageing population that is principally vulnerable $e^{[31,32]}$.

In the present study, RFLP identified $80 \%$ of the samples as genotype 1 , and $20 \%$ samples as genotype 2. Similarly, Abdelrazek et al. ${ }^{[21]}$ found that genotype 1 was more common infecting $88.3 \%$ of cryptosporidiosis patient groups, while genotype 2 infected $11.7 \%$, with no mixed infection. It was reported that genotype 1 is restricted to humans, while genotype 2 infected different animals ${ }^{[24]}$. In contrast, a study on sporadic cases of a small outbreak in the United Kingdom illustrated that genotype 2 isolates were more frequent ${ }^{[33]}$.

Regarding the association of cryptosporidiosis and diarrhea with copro-level of TNF- $\alpha$, our results showed a significant statistical association with cryptosporidiosis $(P=0.02)$. Robinson et $a l^{[19]}$ observed that porcine cryptosporidiosis was linked with histologic evidence of inflammation in the lamina propria assuming that TNF- $\alpha$ has a role in the pathogenesis of cryptosporidiosis. They noticed increased expression of fecal TNF- $\alpha$ post-C. parvum challenge indicating the possibility that TNF- $\alpha$ may synergize some undetermined factors to promote diarrhea in cryptosporidiosis. However, because there was no evident correlation between expression of TNF- $\alpha$ and enteric symptoms, they doubted that diarrhea in human cryptosporidiosis was principally mediated by TNF- $\alpha$. Previously, Kandil et al. ${ }^{[18]}$ suggested that TNF- $\alpha$ was the main mediator of diarrhea in porcine cryptosporidiosis. Seydel et al. ${ }^{[34]}$ added that TNF- $\alpha$ mRNA and protein were also detected in Cryptosporidium infected human intestinal xenografts in immunodeficient mice. In contrast, Alcantara et al. ${ }^{[35]}$ reported that the level of TNF- $\alpha$ was elevated in only one of 14 volunteers and in none of the children with cryptosporidiosis. They explained that this divergence between the stool and intestinal tissue cytokine levels was due to the greater sensitivity of tissue assays and the importance of repeating the assays to identify fecal cytokines. Moreover, proteases and bacteria in the stool samples could have damaged secreted cytokines, leading to falsely low levels.

In the present study, in comparison to nPCR, we found that out of 270 elderly patients, 10 (3.7\%) were positive for Cryptosporidium spp. infection using the AF staining. These results were in accordance with previous results by El-Shazly et al. ${ }^{[23]}$ who detected $5.3 \%$ positivity of cryptosporidiosis in stool samples using $\mathrm{Z} / \mathrm{N}$ stain. In addition, Abd El-Kader et al. ${ }^{[36]}$ recorded a rate of $4.6 \%$ from ten public hospitals in Cairo Governorate. Also, El-Badry et al. ${ }^{[3]}$ reported a prevalence of $7.4 \%$ in Egyptian diarrheic children attending Cairo University hospitals. However, the present results were higher than reported by Yilmaz et $a l^{[38]}$ who found that out of 2000 children, only $1.95 \%$ were positive using microscopy of stained smears. In contrast, our results were lower than Al-Shamiri et al. ${ }^{[39]}$ who recorded $34.7 \%$ positivity of stained smears.

In the present study, the sensitivity, specificity, and accuracy of microscopy were $90 \%, 99.62 \%$, and $99.26 \%$, respectively. A previous study by El-Hamshary et al. ${ }^{[40]}$ certified that the modified Zeihl Neelsen stain provided a lower sensitivity and specificity of $55.3 \%$ and $79 \%$. On the other hand, El-Missiry et al. ${ }^{[41]}$ recorded $100 \%$ sensitivity, specificity, and accuracy of the stain. It is worth mentioning that one sample was positive by microscopy but negative with nPCR. This may be attributed to drawbacks in DNA extraction procedure, such as inefficient nucleic acid isolation or purification. 
Our study showed that on performing the ICT rapid test and ELISA technique to detect Cryptosporidium copro-antigen, 17 (6.3\%) and 18 (6.7\%) were positive, respectively. These results were consistent with ElShazly et $a l .{ }^{[23]}$ and Tahira et $a l .{ }^{[42]}$ who reported the rate of cryptosporidiosis in stool samples using ELISA as 8.3\% and $11.6 \%$, respectively. Moreover, El-Helalya et al. ${ }^{[43]}$ and Helmy et al. ${ }^{[44]}$ recorded $13.6 \%$ and $15.3 \%$ respective positivity of samples by ICT. By ELISA, our results were higher than those of Yilmaz et $a l^{[38]}$ who reported only $4.9 \%$ positive; and by ICT they were distinctly lower than in El-Hamshary et al. ${ }^{[40]}$ who recorded $89.5 \%$ positive cases. Rapid-Quick ICT strip (R-Biopharm, Germany) was employed and the investigators attributed their high positivity to usefulness of the manufactured ICT. Similar results were obtained in the study conducted by Weitzel et al. ${ }^{[45]}$ who reported that the sensitivities of RIDA-Quick, RIDA-Screen, RIDA-Quick Combi and Strip for Cryptosporidium were $88 \%, 82 \%, 82 \%$ and $75 \%$, respectively.

In the present study, the sensitivity, specificity, and accuracy of the ICT $(100 \%, 97.31 \%$, and $97.41 \%)$ and ELISA $(100 \%, 96.92 \%$ and $97.04 \%)$, respectively were distinctly close indicating their reliability. In another study, Zaglool et al. ${ }^{[46]}$ reported that ICT sensitivity was $86.7 \%$ and specificity was $100 \%$, when compared to staining. Controversially, El-Missiry et al. ${ }^{[41]}$ recorded that ICT was $65 \%$ sensitive, $48 \%$ specific, with $50 \%$ accuracy inpatients of different ages: 214 patients $\leq 5$ years, $136 \geq 5$ years; of both sexes, and different immune status. Moreover, El-Settawy and Fathy ${ }^{[47]}$ recorded that ELISA was sensitive (85.7\%) and specific (100\%) with $96.5 \%$ accuracy in diagnosis of cryptosporidiosis compared with nPCR. Our results showed that out of the 17 samples (6.3\%) positive by the ICT rapid test and 18 samples (6.7\%) by the ELISA test, only 10 (3.7\%) were regarded as true positive, i.e. positive by nPCR. On the other hand, 7 samples $(2.6 \%)$ positive by ICT rapid test and 8 samples $(2.9 \%)$ by the ELISA test were considered as false positive since they were negative by both MZN and nPCR techniques. The false positivity may be due to several reasons such as re-infections, mixed infections, the existence of antigens for several days after treatment, and the cross reactivity with other antigens ${ }^{[44,48]}$.

In the present study, we found that 10 cases $(3.7 \%)$ were positive using nPCR, which we considered as the reference method. Previous studies recorded 100\% sensitivity and specificity in diagnosing Cryptosporidium spp. by PCR techniques ${ }^{[20,21]}$. Compared with our results, higher detection rate was documented by El-Hamshary et $a l^{[40]}$ who reported that multiplex PCR succeeded to diagnose cryptosporidiosis in 25\% among diarrheic Egyptian children. Also, Salyer et al. ${ }^{[49]}$ reported a higher rate $(32.4 \%)$ using $n P C R$.

Cryptosporidiosis recorded in our study was relatively higher in males $6(60 \%)$ than females 4 (40\%) without significant association. These results were similarly cited by Qaraman et al. ${ }^{[50]}$ who found that the infection was frequent among males than females. In contrast, Tombang et al. ${ }^{[1]}$ found that Cryptosporidium spp. rate of infection was slightly greater in females $6(5.36 \%)$ than in males $4(3.57 \%)$. Regarding patients' residences, we noticed that the frequency of infection was more in rural areas than urban areas. Similar results were reported by Qaraman et al. ${ }^{[50]}$. Residence in the rural areas seems to be a contributing factor to the intensity of cryptosporidiosis risk due to poor hygiene, overcrowding, low socioeconomic conditions, and possibly contaminated water source ${ }^{[52]}$. In the present study, we found that the infection was equal among patients consuming tap and groundwater. Other studies, verified groundwater as the main source of the infection ${ }^{[53]}$. Xiao and Feng ${ }^{[54]}$ reported that drinking contaminated water is an essential risk factor in the occurrence of cryptosporidiosis that was attributed to the resistance of the infecting stages to chlorine disinfection.

As regards the levels of education, the infection rate showed significant statistical association $(P<0.001)$ with the intermediate group. Al-Shamiri et al. ${ }^{[39]}$ recorded a high percentage in patients with illiterate parents and a low percentage with educated parents and confirmed the significant association $(P=0.001)$ between positivity and the level of parents' education. On the other hand, Khan et al. ${ }^{[55]}$ recorded no significant association among the patients' level of education $(P=0.08)$.

In our work, we found a significant statistical association $(P<0.001)$ between cryptosporidiosis and patients positive for hepatitis C. Previous studies explained that severe liver injury and liver failure are intimately associated with lowered cellular immunity ${ }^{[56]}$. In verification, Mousa et $a l^{[57]}$ reported that $32 \%$ of patients with diarrhea and hepatocellular carcinoma were infected with Cryptosporidium. However, we found no statistical significance between cryptosporidiosis and patients known to be diabetic, which was documented in similar studies ${ }^{[58,59]}$. Drawany et al. ${ }^{[59]}$ explained that patients with DM might be at a higher risk for cryptosporidiosis as the clearance of parasites from the intestine might be impaired due to weakening of both innate and acquired immunities. In addition, we reported no statistical significance between cryptosporidiosis and patients under steroid treatment. In contrast, in another study a higher frequency of cryptosporidiosis parvum was reported in patients taking immunosuppressant medication ${ }^{[60]}$.

In the present study, $100 \%$ and $50 \%$ of patients with cryptosporidiosis presented with abdominal pain and vomiting respectively, being statistically significant with the latter. In this regard, Mirzaei ${ }^{[61]}$ reported that $25.6 \%$ of cryptosporidiosis cases 
had diarrhea; and according to Sajjad et al. ${ }^{[62]}$, patients included in their study had statistically significant diarrhea, abdominal pain, and vomiting. Cryptosporidiosis is a well-recognized reason for diarrhea, volume depletion, and dehydration. It was found that more than two-thirds of the reports that diagnosed cryptosporidiosis recorded volume depletion and that elderly persons may be especially prone to hospitalization due to this complication ${ }^{[31]}$. Though the asymptomatic infection was also relatively common, nonspecific low-grade fever, malaise, nausea, vomiting, and abdominal discomfort may accompany diarrhea. In chronic cases, these symptoms can lead to dehydration, weight loss, and malnutrition ${ }^{[63]}$.

In conclusion, routine follow up of elderly should include stool screening for Cryptosporidium spp. They are considered one of the vulnerable groups due to their weak immunity rendering them more susceptible for opportunistic infections including Cryptosporidium spp. Although cryptosporidiosis significantly affects TNF- $\alpha$ in stool, further studies with larger sample size are recommended to confirm or deny this correlation.

Authors' contribution: All authors contributed to all research measures as teamwork.

Conflict of interest: The authors declare that there is no conflict of interest concerning this study.

Financial statement: The present study did not receive any specific grant from funding agencies.

\section{REFERENCES}

1. Checkley W, White AC, Jaganath D, Arrowood MJ, Chalmers RM, Chen XM et al. A review of the global burden, novel diagnostics, therapeutics, and vaccine targets for Cryptosporidium. Lancet Infect Dis 2015; 15(1):85-94.

2. Gormley FJ, Little CL, Chalmers RM, Rawal N, Adak GK. Zoonotic cryptosporidiosis from petting farms, England and Wales, 1992-2009. Emerg Infect Dis 2011; 17:151-152.

3. Chalmers RM, Campbell B, Crouch N, Davies AP. Clinical laboratory practices for the detection and reporting of Cryptosporidium in community cases of diarrhea in the United Kingdom, 2008. Euro Surveill 2010; 15(48):19731.

4. Tellevik MG, Moyo SJ, Blomberg B, Hjøllo T, Maselle SY, Langeland N, et al. Prevalence of Cryptosporidium parvum/hominis, Entamoeba histolytica and Giardia lamblia among young children with and without diarrhea in Dar Es Salaam, Tanzania. PLoS Negl Trop Dis 2015; 9(10):e0004125.

5. Aghamolaie S, Rostami A, Havildar Biderouni F, Haghighi A. Evaluation of modified Ziehl-Neelsen, direct fluorescent-antibody and PCR assay for detection of Cryptosporidium spp. in children fecal specimens. J Parasit Dis 2016; 40(3):958-963.
6. Xiao L. Molecular epidemiology of cryptosporidiosis: an update. Exp Parasitol 2010; 124: 80-89.

7. Neill MA, Rice SK, Ahmad NV, Flanigan TP. Cryptosporidiosis: an unrecognized cause of diarrhea in elderly hospitalized patients. Clin Infect Dis 1996; 22:168-170.

8. Starusbaugh LJ. Emerging health care-associated infections in the geriatric population. Emerg Infect Dis 2001; 7:268-271.

9. Craun GF, Calderon RL. Workshop summary: Estimating waterborne disease risks in the United States. J Water Health 2006; 4(2):241-253.

10. Efstratiou A, Ongerth JE, Karanis P. Waterborne transmission of protozoan parasites: review of worldwide outbreaks-an update 2011-2016. Water Res 2017; 114:14-22.

11. Squire SA, Ryan U. Cryptosporidium and Giardia in Africa: current and future challenges, Parasit Vectors 2017; 10(1):195.

12. Agnamey P, Sarfati C, Pinel C, Rabodoniriina M, Kapel $\mathrm{N}$, Dutoit $\mathrm{E}$, et al. Evaluation of four commercial rapid immunochromatographic assays for detection of Cryptosporidium antigens in stool samples: A blind multicenter trial. J Clin Microbiol 2011; 49(4):16051607.

13. Kabir M, Ahmed E, Hossain B, Alam M, Ahmed S,Taniuchi M, et al. Quik check assay is more specific than quantitative polymerase chain reaction for rapid point-of-care diagnosis of cryptosporidiosis in infants in Bangladesh. Clin Infect Dis 2018; 67(12):18971903.

14. Bruijnesteijn van Coppenraet LE, Wallinga JA, Ruijs GJ,Bruins MJ, Verweij JJ. Parasitological diagnosis combining an internally controlled real-time PCR assay for the detection of four protozoa in stool samples with a testing algorithm for microscopy. Clin Microbiol Infect 2009; 15:869-874.

15. Elwin K, Hadfield SJ, Robinson G, Crouch ND, Chalmers RM. Cryptosporidium viatorum n.sp. (Apicomplexa: Cryptosporidiidae) among travelers returning to Great Britain from the Indian subcontinent, 20072011. Int J Parasitol 2007; 42:675-682.

16. Del Chierico F, Onori M, Di Bella S, Bordi E, PetrosilloN, Menichella D et al. Cases of cryptosporidiosis coinfections in AIDS patients: A correlation between clinical presentation and GP60 subgenotype lineages from aged formalin-fixed stool samples. Ann Trop Med Parasitol 2011; 105:339-349.

17. Sharma P, Sharma A, Sehgal R, Malla N, Khurana S. Genetic diversity of Cryptosporidium isolates from patients in North India. Int J Infect Dis 2013; 17: e601-605.

18. Kandil HM, Berschneider HM, Argenzio RA. Tumor necrosis factor alpha changes porcine intestinal ion transport through a paracrine mechanism involving prostaglandins. Gut 1994; 35:934-940.

19. Robinson P, Okhuysen PC, Chappell CL, Lewis DE, Shahab I, Janecki A, et al. Expression of tumor necrosis factor alpha and interleukin 1 beta in jejuna 
of volunteers after experimental challenge with Cryptosporidium parvum correlates with exposure but not with symptoms. Infect Immun2001; 69(2):11721174 .

20. Tahvildar-Biderouni F, SalehiN. Detection of Cryptosporidium infection by modified Ziehl Neelsen and PCR methods in children with diarrheal samples in pediatric hospitals in Tehran. Gastroenterol Hepatol Bed Bench 2014; 7(2):125-130.

21. Abdelrazek NM, Al-Antably ASA, Fathy MM, ElBadry AA. Copro-molecular characterization of Cryptosporidium spp. and genotypes among Egyptian children. J Egypt Soc Parasitol 2016; 46(2):375-386.

22. Garcia LS. Diagnostic Medical Parasitology, $5^{\text {th }}$ ed. ASM Press, Washington DC. 2007.

23. El-Shazly AM, Atta M, El-Meniawy MA. The use of Ziehl-Neelsen stain, enzyme linked immunosorbent assay and nested polymerase chain reaction in diagnosis of cryptosporidiosis in immunocompetent and immunocompromised patients, J Egypt Soc Parasitol 2002; 32:155 -166.

24. Pedraza-Díaz S, Amar C, Nichols GL, McLauchlin J. Nested polymerase chain reaction for amplification of the Cryptosporidium oocyst wall protein gene. Emerg Infect Dis 2001; 7(1):49-56.

25. Spano F, Putignani L, McLauchlin J, Casemore D, Crisanti A. PCR-RFLP analysis of the Cryptosporidium oocyst wall protein (cowp) gene discriminates between $C$. wrairi and $C$. parvum, and between $C$. parvum isolates of human and animal origin. FEMS Microbiol Lett 1997; 150(2):209-217.

26. Nicholls S, Stephens S, Braegger CP, Walker-Smith JA, MacDonald TT. Cytokines in stools of children with inflammatory bowel disease or infective diarrhoea. J Clin Pathol 1993; 46(8):757-760.

27. Chan YH. Biostatistics 102: Quantitative data: Parametric and non-parametric tests. Singapore Med J 2003; 44(8):391-396.

28. Chan YH. Biostatistics 103: Qualitative data: Tests of independence. Singapore Med J 2003; 44(10):498-503.

29. Galen RS. Predictive value and efficiency of laboratory testing. Pediatr Clin North Am 1980; 27(4):861-869.

30. Naumova EN, Egorov AI, Morris RD, Griffiths JK. The elderly and waterborne Cryptosporidium infection: gastroenteritis hospitalizations before and during the 1993 Milwaukee outbreak. Emerg Infect Dis 2003; 9(4):418-425.

31. Mor SM, DeMaria AJr, Griffiths JK, Naumova EN. Cryptosporidiosis in the elderly population of the United States. Clin Infect Dis 2009; 48(6):698-705.

32. Gerba CP, Rose JB, Haas CN. Sensitive populations: who is at the greatest risk? Int J Food Microbiol 1996; 30:113-123.

33. Guyot K, Follet-Dumoulin A, Lelièvre E, Sarfati C, Rabodonirina M, Nevez G et al. Molecular characterization of Cryptosporidium isolates obtained from humans in France. J Clin Microbiol 2001; 39(10):3472-3480.

34. Seydel KB, Zhang T, Champion GA, Fichtenbaum C, SwansonPE, Tzipori S, et al. Cryptosporidium parvum infection of human intestinal xenografts in SCID mice induces production of human tumor necrosis factor alpha and interleukin-8. Infect Immun 1998; 66:2379-2382.

35. Alcantara CS, Yang CH, Steiner TS, Barrett LJ, Lima AA, Chappell CL, et al. Interleukin-8, tumor necrosis factor alpha and lactoferrin in immunocompetent hosts with experimental and Brazilian children with acquired cryptosporidiosis. Am J Trop Med Hyg 2003; 68(3): 325-328.

36. Abd El Kader NM, Blanco MA, Ali-Tammam M, Abd El Ghaffar AR, Osman A, El Sheikh N, et al. Detection of Cryptosporidium parvum and Cryptosporidium hominis in human patients in Cairo, Egypt. Parasitol Res 2012; 110: 161-166.

37. El-Badry AA, Al-Antably AS, Hassan MA, Hanafy NA, Abu-Sarea EY. Molecular seasonal, age and gender distributions of Cryptosporidium in diarrheic Egyptians: Distinct endemicity. Eur J Clin Microbiol Infect Dis 2015; 34:2447-2453.

38. Yilmaz H, Tas-Cengiz Z, Cicek M. Investigation of cryptosporidiosis by enzyme-linked immunosorbent assay and microscopy in children with diarrhea. Saudi Med J 2008; 29(4):526-529.

39. Al-Shamiri AH, Al-Zubairy AH, Al-Mamari RF. The Prevalence of Cryptosporidium spp. in children, Taiz District, Yemen. Iran J Parasitol 2010; 5(2):26-32.

40. El-Hamshary EM, El-Sayed HF, Hussein EM, Rayan HZ, Soliman RH. Comparison of polymerase chain reaction, immunochromatographic assay and staining techniques in diagnosis of cryptosporidiosis. PUJ 2008; 1(2):77-86.

41. El-Missiry GA, Abd El-Hameed LME, Saad GA, ElBadry AA, Helmy AY, Shehata AM. Molecular genetic characterization of human Cryptosporidium isolates and their respective demographic, environmental and clinical manifestations in Egyptian diarrheic patients. PUJ 2019; 12(3):187-196.

42. Tahira F, Khan HM, Shukla I, Shujatullah F, Malik MA, Shahid M, et al. Prevalence of Cryptosporidium in children with diarrhea in North Indian Tertiary Care Hospital. J Comm Med Hlth Edu 2012; 2:136-139.

43. El-Helalya NS, Alyb MM, Attiab SS. Detection of Cryptosporidium infection among children with diarrhea. NY Sci J 2012; 5:68-76.

44. Helmy YA, Krücken J, Nckler K, Samson-Himmelstjerna G, Zessin KH. Comparison between two commercially available serological tests and polymerase chain reaction in the diagnosis of Cryptosporidium in animals and diarrheic children. Parasitol Res 2014; 113(1):211-216.

45. Weitzel T, Dittrich S, Möhl I, Adusu E, Jelinek T. Evaluation of seven commercial antigen detection tests for Giardia and Cryptosporidium in stool samples. Clin Microbiol Infect 2006; 12(7):656-659.

46. Zaglool DAM, Mohamed A, Khodari YA, Farooq MU. Crypto-Giardia antigen rapid test versus conventional modified Ziehl-Neelsen acid fast staining method for diagnosis of cryptosporidiosis. Asian Pacif J Trop Med 2013; 6(3):212-215. 
47. El-Settawy MA, Fathy GM. Evaluation and comparison of PCR, coproantigen ELISA and microscopy for diagnosis of Cryptosporidium in human diarrheic specimens. J Am Sci 2012; 8(12):2505-2511.

48. Cama VA, Bern C, Roberts J, Cabrera L, Sterling CR, Ortega Y, et al. Cryptosporidium species and subtypes and clinical manifestations in children, Peru. Emerg Infect Dis 2008; 14(10):1567-1574.

49. Salyer SJ, Gillespie TR, Rwego IB, Chapman CA, Goldberg TL. Epidemiology and molecular relationships of Cryptosporidium spp. in people, primates, and livestock from Western Uganda. PLoS Negl Trop Dis 2012; 6(4):e1597.

50. Qaraman MK, Abbas MF.Prevalence of Cryptosporidium spp. with other intestinal microorganisms among regular visitors of Raparin Pediatric Hospital in Erbil City-Kurdistan Region, Iraq. Zanco J Pure Appl Sci 2015;27(4):174-180.

51. Tombang AN, Ambe NF, Bobga TP, Nkfusai CN, Collins NM, Ngwa SB, et al. Prevalence and risk factors associated with cryptosporidiosis among children within the ages 0-5 years attending the Limbe regional hospital, southwest region, Cameroon. BMC Public Health 2019;19(1):1144.

52. Yu JR, Lee JK, Seo M, Kim SI, Sohn WM, Huh S et al. Prevalence of cryptosporidiosis among the villagers and domestic animals in several rural areas of Korea, Korean J Parasitol 2004; 42(1):1-6.

53. Yacoub. Intestinal protozoa and Cryptosporidium genotypes in children with diarrhea in Northern Palestine, Master Thesis, AlNagah National University, Palestine, 2014.

54. Xiao L, Feng Y. Zoonotic cryptosporidiosis. Immunol Med Microbiol 2010; 52(3):309-323.

55. Khan A, Shams S, Khan S, Khan MI, Khan S, Ali A. Evaluation of prevalence and risk factors associated with Cryptosporidium infection in rural population of district Buner, Pakistan. PLoS One 2019; 14(1): e0209188.

56. Wasmuth H, Kunz D, Yagmur E, Timmer-Stranghöner A, Vidacek D, Siewert E, et al. Patients with acute or chronic liver failure display 'sepsis-like' immune paralysis. J Hepatol 2005; 42:195-201.

57. Mousa N, Abdel-Razik A, El-Nahas H, El-Shazly A, Abdelaziz $\mathrm{M}$, Nabih $\mathrm{M}$, et al. Cryptosporidiosis in patients with diarrhea and chronic liver diseases. J Infect Dev Ctries 2014; 8(12):1584-1590.

58. Akhlaghi L, Gharavi M, Faghihi A, Jabbari M. Survey on the prevalence rates of intestinal parasites in diabetic patients in Karaj and Savodjbolagh cities. Razi j Med Sci 2005; 12(45):23-29.

59. Drawany ZEE, Saleh SHA, Etewa SES, Ibrahim S M. Prevalence of intestinal parasites among type 1 diabetic patients in pediatrics Zagazig university hospital. Endocrinol Metab Int J 2019; 7(6):171-179.

60. Nic Lochlainn LM, Sane J, Schimmer B, Mooij S, Roelfsema J, van Pelt W, et al. Risk factors for sporadic cryptosporidiosis in the Netherlands: Analysis of a 3-Year population based case-control study coupled with genotyping, 2013-2016. J Infect Dis 2019; 219(7):1121-1129.

61. Mirzaei M. Prevalence of Cryptosporidium sp. infection in diarrhea and non-diarrheic humans in Iran. Korean J Parasitol 2007; 45(2):133-143.

62. Sajjad A, Sunil M, Kiran K, Kapeel R, Shehla B. Prevalence, clinical presentation and treatment outcome of cryptosporidiosis in immunocompetent adult patients presenting with acute diarrhea. J Pak Med Assoc 2014; 64(6):613-618.

63. Derouin F, Dutoit F, de Motibrison F. Cryptosporidium laboratory-based surveillance for Cryptosporidium to France, 2006-2009. Euro Survell 2010; 15(33): 19642- 19649. 